\title{
Reformas na Educação Superior: de FHC a Dilma Rousseff (1995-2011)
}

Suely Ferreira

Universidade Federal de Goiás

\section{Resumo}

As mudanças nas últimas décadas do século XX e início do século XXI, na universidade, no Estado e no mercado vêm promovendo alterações substantivas na forma de conceber a universidade e o exercício das suas finalidades nessa relação em inúmeros países. Esse processo vem requerendo que as universidades se integrem às demandas da reestruturação produtiva do capital. Em relação às universidades no Brasil, objetivou-se discutir as novas concepções e finalidades sociais que vêm sendo construídas para essas instituições, no contexto das reformas da educação superior, durante os governos de Fernando Henrique Cardoso e de Lula da Silva e no início do governo de Dilma Rousseff.

Palavras-chave: Universidade. Reformas. Finalidades sociais. 


\section{Reforms in Higher Education: from FHC to Dilma Rousseff (1995-2011)}

Changes in the last decades of the twentieth century and beginning of the twenty-first, in the university, the state and the market, have promoted substantial changes in the conception of the University and of the way it goes about fulfilling its purposes, in this context, in several countries. This process has required universities to respond to the demands for productive restructuring of capital. As to universities in Brazil, the goal is to discuss the new conceptions and social purposes that have been constructed for these institutions, in the context of the reforms in social education, during the presidencies of Fernando Henrique Cardoso and Lula da Silva, and the beginning of Dilma Rouseff's.

Keywords: University. Reform. Social purposes.

\section{Reformas en la Educación Superior: de FHC a Dilma Rousseff (1995-2011)}

Los cambios en las últimas décadas del siglo XX y en el inicio del siglo XXI, en la universidad, en el Estado y en el mercado, han promovido alteraciones significativas en innumerables países, en la forma de concebir la universidad y el ejercicio de sus finalidades en esa relación. Ese proceso está requiriendo que las universidades se integren con las demandas de la reestructuración productiva del capital. Con relación a las universidades brasileñas, el objetivo fue discutir las nuevas concepciones y las finalidades sociales que han sido construidas para esas instituciones, en el contexto de las reformas de la educación superior, durante los gobiernos de Fernando Henrique Cardoso y de Lula da Silva, así como en el inicio del gobierno de Dilma Rousseff.

Palabras clave: Universidad. Reformas. Finalidades sociales. 


\section{Introdução}

As mudanças substantivas que sofrem as universidades nas últimas décadas expressam um movimento dialético que envolve os aspectos tanto internos quanto externos dessas instituições e levam a que se situem não somente no contexto nacional, mas no âmbito da internacionalização da educação superior. Acentua-se o debate da necessidade das universidades se readequarem e assumirem novos fins consonantes com as aceleradas transformações decorrentes da reestruturação produtiva do capital e da própria reconfiguração dos estados em vários países do globo, sobretudo a partir dos anos 1980. Ao mesmo tempo, ganha expressão a perspectiva de que a sociedade e a economia devem estar assentadas no conhecimento como estratégia de competitividade, tanto no cenário local quanto no internacional. Nesse referencial, a existência da universidade em si mesma não bastaria mais como fator da sua legitimação social, diante da constatação de que "a forma como hoje é discutido o papel do ensino superior tem sido significativamente influenciada por considerações econômicas" (Teixeira, 2009, p. 9), na medida em que a ciência e a educação superior passaram a ser consideradas como fatores de produção e "parte integrante da economia, mercadorias ou quase mercadorias, em países centrais, da periferia e da semiperiferia" (Sguissardi, 2006, p. 1035). Visando entender como esse processo vem influenciando a reconfiguração das finalidades sociais das universidades no Brasil, o trabalho analisa as reformas na educação superior no período de 1995 a 2011.

\section{A reforma da educação superior no governo Fernando Henrique Cardoso (FHC): diretrizes para um novo modelo?}

O governo de Fernando Henrique Cardoso (1995-2002) levou avante o processo de "modernização" conservadora (racionalidade administrativa e eficácia quantitativa) iniciado pelo governo de Collor de Mello (1990-1992) e de Itamar Franco (1992-1994)'. No governo de FHC, ocorreram medidas de ajustes estruturais e fiscais, bem como reformas orientadas para o mercado, visando à integração do Brasil à economia mundial, ao mesmo tempo em que se enfatizava o novo papel atribuído ao mercado para alocação dos recursos e se diminuíam as funções do Estado como provedor dos serviços. Para Silva Júnior, essa orientação propiciou um novo paradigma para as políticas públicas, ou seja,

1. Em relação ao discurso da "modernização da universidade", Chauí explica que o referencial era "criar a 'universidade de serviços', baseada na docência e pesquisa 'de resultados'”(2001, p.166). 
as políticas públicas de oferta a serem executadas na sociedade civil em geral por ONGs, movimento que ao lado das reformas institucionais, com destaque para as educacionais, buscou redesenhar nossa sociabilidade, e criou condições para a produção de um novo paradigma político orientado pelo instrumental, pela adaptação e a busca do consenso (traço político assumido [...] e cultura política defendida [inclusive] pelo presidente Lula por meio de seu Pacto Social). (Silva Júnior, 2007, p. 97).

Em relação às políticas educacionais, Corbucci (2004) afirma que o governo FHC favoreceu-se das medidas adotadas das gestões anteriores no que tange à política do Ministério da Educação (MEC), principalmente na questão da extinção do Conselho Federal de Educação (CFE) e da criação do Conselho Nacional de Educação (CNE), que possibilitou fossem delegadas maiores responsabilidades ao setor privado para a expansão da educação superior. Ainda segundo o autor, a criação do CNE conferiu maior autonomia

na condução do processo de expansão do ensino e graduação, ao assumir funções deliberativas, até então prerrogativas do CFE. [...] Foram acelerados e facilitados os processos de autorização, reconhecimento e credenciamento de cursos e instituições do setor privado, por parte do CNE. Com isso, favoreceu-se consideravelmente a expansão desse nível de ensino, por intermédio da iniciativa privada. (Corbucci, 2004, p. 682).

Na visão de Cunha, a proposta de governo de FHC para a educação superior destacou-se pela preponderância do papel econômico a ela atribuído, como a

'base do novo estilo de desenvolvimento', cujo dinamismo e sustentação provém de fora dela mesma - do progresso científico e tecnológico. [...] Afirmava a necessidade de se estabelecer uma "verdadeira parceria" entre o setor privado e governo, entre universidade e indústria, tanto na gestão quanto no financiamento do sistema brasileiro de desenvolvimento científico e tecnológico. [...] A política para o ensino superior deveria promover uma "revolução administrativa": o objetivo seria administração mais racional dos recursos e a utilização da capacidade ociosa, visando a generalizar os cursos noturnos e aumentar as matrículas, sem despesas adicionais. Para isso, as universidades deveriam ter uma "efetiva autonomia", mas que condicionasse o montante de verbas que viessem a receber à avaliação de desempenho. (Cunha, 2003, p. 39).

De acordo com Corbucci, o Plano Plurianual do governo FHC referente ao período 1996-1999 reconhecia a posição desvantajosa do Brasil em relação aos outros países no quesito Ciência \& Tecnologia e defendia que o país deveria preparar-se para a abertura da economia e a sua inserção no processo de globalização. Porém, “a 
despeito dessas diretrizes políticas integrantes dos discursos oficiais, os dispêndios do MEC com a educação superior, em especial aqueles destinados à manutenção da rede federal, foram sistematicamente contingenciados ao longo da década de 1990" (Corbucci, 2004, p. 681).

Na década de 1990, a reforma promovida na educação superior caracterizou-se por uma reorganização das universidades que seguiu uma orientação política que se subordinava às regras do mercado mediante a competitividade por autofinanciamento, e por uma racionalidade técnica que levava a uma especialização das Instituições de Educação Superior (IES) em áreas de competência que visavam a potencializar os recursos para alcançar maior eficiência e competitividade (Oliveira, 2000). Essa nova lógica passou a exigir das Universidades Federais (UFs):

a) definir a natureza/identidade e missão básica que possui no cenário acadêmico; b) definir as reais vocações e potencialidades específicas; cl contribuir decisivamente para o desenvolvimento do Estado e da região em que se insere; d) expandir as vagas, sobretudo no período noturno, sem ampliar o quadro de docentes e técnicoadministrativos, objetivando aumentar a relação aluno/professor; el otimizar a utilização das instalações físicas e dos equipamentos, bem como das habilidades docentes; f) diminuir as taxas de reprovação e evasão; $g$ ) reduzir os recursos destinados à residência estudantil, restaurantes, bolsas e subsídios; h) flexibilizar o ensino, os cursos, os currículos e os programas de estudo; i) melhorar a qualidade do ensino oferecido; j) adequar os cursos de formação e os serviços às demandas do mercado de trabalho; ll aperfeiçoar mecanismos de avaliação; ml qualificar a gestão, racionalizar o uso de recursos e estimular a produtividade; $n$ ) buscar alternativas de financiamento; ol flexibilizar a política de pessoal docente e técnico-administrativo; pl qualificar e titular docentes e servidores; q) integrar pós-graduação/graduação; r) consolidar a pesquisa e os programas de pós-graduação; s) ampliar a produção e capacidade científica instalada; t) desenvolver processos de inovação tecnológica de produção e difusão da ciência e da cultura; u) exercer ampla autonomia. (Oliveira, 2000, p. 75-76. Grifado no original).

Nesse cenário, desenhou-se um novo projeto pedagógico para a educação superior brasileira, consonante com as novas demandas do capital internacional e com as recomendações de organismos multilaterais. Em dezembro de 1996, foi promulgada a Lei $n^{0}$ 9.394, de 20 de dezembro de 1996, a Lei de Diretrizes e Bases da Educação Nacional (LDB), que possibilitou um novo ordenamento jurídico para a educação e introduziu inúmeras modificações no campo da educação superior. Dentre delas, devem-se ressaltar as seguintes: a exitstência de instituições de ensino superior públicas ou privadas, com variados graus de abrangência ou especialização (art. 45 da LDB); a distinção entre as IES públicas, IES privadas sem fins lucrativos 
e IES privadas com fins lucrativos (Decreto $n^{\circ} 2.306$, de 19 de agosto de 1997); a diversificação das IES, ao mudar sua organização acadêmica para universidades, centros universitários, faculdades integradas, faculdades, institutos superiores ou escolas superiores (art. $4^{\circ}$ do Decreto $\left.n^{0} 2.306 / 1997\right)$ ). Também o parágrafo único do art. 52 da LDB propiciou nova possibilidade de caracterização para as universidades: "É facultada a criação de universidades especializadas por campo do saber". Esse novo tipo de IES introduziu uma modificação substantiva em relação à natureza e à identidade das universidades tradicionais.

Quanto aos centros universitários, foram criados com objetivo de se constituírem em instituições de ensino pluricurriculares, abrangendo uma ou mais áreas do conhecimento, caracterizando-se pela excelência de ensino, ganhando autonomia para criar, organizar e extinguir, em sua sede, cursos e programas de educação superior, além de outras atribuições. Essa nova organização das IES tende, por meio da sua diversificação, a romper com a indissociabilidade entre ensino, pesquisa e extensão, uma vez que se exige somente das instituições universitárias essa articulação. Vale ressaltar que a LDB, em seu art. 44, inciso I, introduziu também um novo tipo de curso, os chamados cursos sequenciais, por campo de saber, por diferentes níveis de abrangência. Os argumentos que defendiam sua criação asseguravam que esse novo percurso seria uma alternativa aos tradicionais cursos de graduação, promovendo a flexibilidade e a sintonia com as demandas do mercado de trabalho.

No governo de FHC também foram introduzidas várias medidas de reestruturação para a educação superior e para as universidades públicas. Vale destacar: a) Lei ${ }^{0}$ 10.260, de 7 de dezembro de 2001, que dispôs sobre o Fundo de Financiamento do Estudante do Ensino Superior (FIES) e que possibilitou, indiretamente, a alocação de verbas públicas para as instituições privadas, com avaliação considerada positiva, assegurando o preenchimento de parte das vagas do setor privado ${ }^{2}$; b) Lei no 10.168, de 29 de dezembro de 2000, que estabeleceu o Programa de Estímulo à Interação Universidade-Empresa para o Apoio à Inovação a partir de parcerias entre universidades, centros de pesquisa e o setor privado; c) Lei no 10.172 , de 9 de janeiro de 2001, que aprovou o Plano Nacional de Educação, com vários vetos que explicitaram a transferência de responsabilidades do poder público para a sociedade no financiamento da educação.

0 processo de reforma da educação superior na década de 1990 orientouse por um perfil pragmático que implicou alterações na concepção e organização

2. A Lei n 9.131, de 24 de novembro de 1995, criou o Exame Nacional de Cursos (ENC) e a avaliação das condições de oferta dos cursos de graduação, pelo Decreto $n^{0} 2.026$, de 10 de outubro de 1996 . A avaliação considerada positiva obedecia a dois critérios básicos: cursos regularmente reconhecidos e que não obtiveram os conceitos D e E nas três últimas avaliações. A escala das notas em ordem decrescente era esta: $A, B, C, D, E$. 
desse nível de educação. Essas alterações se deram mediante as mudanças na legislação educacional, ao se relegar a segundo plano o setor público, no incentivo para diversificar as fontes de financiamento e para a diferenciação institucional, na expansão do acesso na esfera predominantemente privada, na precarização da qualidade e na redução da autonomia universitária (Dourado, 2008). A política para a educação superior delineada nesse período propôs a redução de recursos destinados à educação, no contexto da lógica neoliberal de contenção dos gastos públicos. A redução drástica do financiamento das instituições públicas mediante o fundo público, no governo FHC, levou as universidades federais a voltarem-se para as atividades

de prestações de serviços, oferecendo cursos, assessorias e consultorias remuneradas e assim elas passa[ram] a enfrentar dois pólos de controle: o estatal e o do mercado [...]. A instituição pública passa [nesse contexto] a depender sutilmente da avaliação que o mercado faz da qualidade de seus "serviços" e efetiva-se uma verdadeira vinculação entre avaliação do mercado e volume de recursos financeiros que a instituição pública consegue captar, em geral, utilizando-se das fundações de apoio de caráter privado. (Amaral, 2009, p.134-5).

No governo de FHC, as diretrizes políticas passaram pela tentativa da caracterização da educação superior como um serviço público não estatal; da diminuição significativa do financiamento estatal na manutenção das universidades federais; da mudança do papel do Estado, de financiador para regulador; da privatização; do incentivo de fontes alternativas de financiamento; das parcerias público-privadas; da diferenciação e competitividade entre instituições; da expansão de baixo custo; do ensino a distância; dos sistemas de avaliação; da formação para atender ao mercado de trabalho. Nessa perspectiva, as universidades passaram a ser vistas a partir de uma visão mais pragmática e utilitária dos seus serviços, seja na formação profissional, seja na produção da ciência e da tecnologia, modificando expressivamente os referenciais da sua finalidade e relevância social.

\section{A reforma da educação superior do governo Lula da Silva (2003-2010): qual modelo para as universidades?}

A reforma da educação superior no governo Lula foi guiada por meio da promulgação de leis e decretos que apontaram mais para a continuidade do que para a ruptura com as políticas para a educação superior estabelecidas no governo FHC, apesar de ter havido, no período de 2004 e 2006, aumento de recursos públicos para as instituições federais de educação superior (Ifes), o que refletiu na "contratação 
de novos professores e servidores técnico-administrativos e expansão dos campi situados no interior dos Estados" (Amaral, 2008, p. 667). Para demonstrar como se efetivou a reforma da educação superior no governo Lula, cabe destacar algumas ações, consubstanciadas nos textos normativos citados a seguir:

a) Lei $n^{0}$ 10.861, de 14 de abril de 2004, que instituiu o Sistema Nacional de Avaliação da Educação Superior (SINAES), em substituição ao ENC, e a avaliação das condições de oferta dos cursos de graduação do governo FHC. A lei passou a sofrer várias críticas, entre elas a de conter uma lógica produtivista e meritocrática, em que o Estado prioriza o seu papel de avaliador e regulador.

b) Lei n 10.973 , de 2 de dezembro de 2004, a chamada Lei de Inovação Tecnológica, que tratou de incentivos à inovação e à pesquisa científica e tecnológica no ambiente produtivo. A lei permite a naturalização da aproximação entre conhecimento e mercado, bem como entre universidade e setor privado, possibilitando a subordinação da pesquisa científica e tecnológica às exigências do setor produtivo privado.

c) Lei no 11.079, de 30 de dezembro de 2004, que introduziu as normas gerais para licitação e contratação de Parceria Público-Privada no âmbito da administração pública, permitindo ao Governo Federal contratar parcerias público-privadas. A crítica, para o caso da educação, é que, "para além do fortalecimento do pólo privado do Estado ou como parte dele, amplia-se a utilização dos recursos públicos por entidades privadas, com ou sem fins lucrativos" (Sguissardi, 2006, p. 1.043).

d) Decreto Presidencial n 5.225, de $1^{\circ}$ de outubro de 2004, que dispôs sobre a organização dos Centros Federais de Educação Tecnológica, e, posteriormente, a Lei no 11.892, de 29 de dezembro de 2008, que instituiu a Rede Federal de Educação Profissional, Científica e Tecnológica e criou os Institutos Federais de Educação, Ciência e Tecnologia (IFs).

e) Lei n 11.096, de 13 de janeiro de 2005, que criou o Programa Universidade para Todos (ProUni) e normatizou a atuação de entidades beneficentes de assistência social na educação superior. O ProUni representou uma tentativa diferenciada do governo Lula em relação ao governo FHC de tratar a expansão do ensino superior ao "associar o financiamento estatal das instituições privadas com e sem fins lucrativos, por meio da isenção fiscal, à incorporação de parcela da população estudantil historicamente sub-representada no sistema da educação superior" (Gomes, 2008, p. 30), trabalhando, assim, uma nova matriz discursiva para ressignificar tanto a ampliação como a expansão desse nível de educação. Já de acordo com Catani e Hey, um dos grandes 
dilemas da educação superior refere-se à ampliação do acesso e às atuais tendências das políticas de acesso, como o ProUni e o crédito educativo. Os autores demonstram que a "configuração do sistema de educação superior no país - marcada pela hegemonia do setor privado na oferta de vagas - tende a se consolidar, já que atendem à ampliação do acesso com a manutenção da estrutura de oferta de vagas nesse setor" (Catani e Hey, 2007, p. 414).

f) Decreto Presidencial $n^{0} 5.205$, de 14 de setembro de 2004, que regulamentou as fundações de apoio privadas no interior das instituições federais de ensino superior.

g) Decreto Presidencial $n^{0}$ 5.622, de 19 de dezembro de 2005, que normatizou a educação a distância, fortalecendo a abertura do mercado educacional ao capital estrangeiro. Anterior ao ano de 2005, a Portaria $n^{0} 4.059$, de 10 de dezembro de 2004, passou a permitir a educação a distância nos cursos regulares. Lima chama a atenção para a concepção da educação como política de "integração dos países periféricos à globalização econômica e à sociedade da informação e a utilização das TIC, que já aparece nos países periféricos reduzida à EAD, é apresentada como o passaporte da educação para a sociedade da informação" (Lima, 2007, p. 183).

h) Decreto $n^{0}$ 6.096, de 24 de abril de 2007, que instituiu o Programa de Apoio a Planos de Reestruturação e Expansão das Universidades Federais (Reuni). São algumas das metas do Reuni que devem ser cumpridas pelas universidades até 2012: aumentar as vagas nos cursos de graduação, ampliar os cursos noturnos, propiciar inovações pedagógicas (revisar estrutura acadêmica, atualizar metodologias de ensino e aprendizagem, diversificar modalidades de graduação), combater a evasão, elevar a taxa de aprovação para 90\%, atingir a proporção de 18 alunos por professor, ampliar a mobilidade estudantil entre as instituições, cursos e programas de educação superior. As universidades que aderirem ao programa terão um plus de financiamento lacréscimo de recursos até o limite de $20 \%$ das despesas de custeiol para atingir as metas.

Para Maués, os programas de governo de Lula, como o SINAES, a Lei de Inovação Tecnológica, a Parceria Público-Privada e o Reuni constituíram uma nova regulação social para o campo da educação superior. Maués, com base em Lessar, explicita que esses mecanismos colocaram a "obrigação de resultados que exprime uma pressão social forte em favor de um sistema educacional mais 'performático'" (Maués, 2008, p. 12). Sobre os programas do ProUni e do Reuni podemos afirmar que foram as opções desse governo para ampliar o acesso à educação superior. Os programas citados parecem constituir-se em programas de Estado, uma vez que o governo Dilma dá continuidade aos programas, inclusive reafirmando uma nova etapa para o Reuni. 
Vale ainda lembrar que o Plano de Desenvolvimento da Educação (PDE) publicado em 2007 também ratificou o Reuni, ao estabelecer a

expansão dos cursos noturnos, a ampliação da mobilidade estudantil, a revisão da estrutura acadêmica e a diversificação das modalidades de graduação. Itinerários rígidos, desperdício de créditos, imobilidade e especialização precoce são incompatíveis com uma estrutura universitária à altura dos novos desafios da ciência. (BRASIL, 2007, p. 27-28).

O PDE aprovado pelo governo Lula surgiu à margem e independente do Plano Nacional de Educação (2001-2010). Inclusive havia uma expectativa de que o governo Lula derrubaria os vetos impostos por FHC ao PNE, principalmente no que se referia ao financiamento, como, por exemplo, elevar o percentual de gasto público em relação ao PIB para atingir 7\%, o que não ocorreu.

Nesse cenário, a política para educação superior do governo Lula mostrou-se

bastante contraditória, tanto no discurso como na práxis. No discurso presidencial, por um lado, afirma a educação superior como um bem público imbuído de função social, mas, ao mesmo tempo, justifica, constantemente, seu gasto por trazer um retorno econômico futuro à sociedade, nos moldes da lógica do investimento em capital humano, enfatizada nos documentos do BIRD. Na prática, por um lado, estreitou as relações público/ privado e optou pela solvência das IES privadas através do ProUni, bem como manteve e até mesmo aprofundou os parâmetros avaliativos e a função regulatória do Estado através do SINAES, mas, por outro, reverteu, em parte, o processo de sucateamento do segmento federal e de desvalorização do serviço público em geral, inclusive, com a reposição salarial e dos quadros funcionais. (Carvalho, 2006, p. 11-2).

Em relação à implementação do programa "Expandir", em 2006, pelo governo Lula, por meio da expansão das Ifes (criação de dez novas universidades e 48 campi e ampliação da rede federal de educação tecnológica e profissional), da fundação da Universidade Aberta do Brasil (2006) e do Reuni (2007), pode-se dizer que, apesar do caráter gerencialista3 assumido na gestão dos programas, denotou-se uma nova postura referente à expansão da educação superior no âmbito do público em relação ao governo FHC (Dantas; Sousa Júnior, 2009). Os autores ainda discorrem que

o primeiro governo Lula encetou uma lenta transição para um novo modelo, partindo da flexibilização do padrão adotado no governo anterior e incorporando

3. Dantas e Sousa Júnior entendem o caráter gerencialista como "mecanismos de gestão privada introduzidos no setor público, induzindo-o a adotar critérios, ações e controle nos moldes que o mercado persegue na busca do lucro" (Dantas; Sousa Júnior, 2009, p. 6). 
grande parte de sua agenda, especialmente, a questão do gerencialismo. As mudanças ocorridas no governo a partir do final de 2005 promoveram uma alteração gradual na condução da política do governo, reorientando-o no sentido de uma maior intervenção do Estado, seja na economia, seja no âmbito das políticas sociais, repondo a agenda de intervenção do Estado e do planejamento como instrumento de indução do desenvolvimento (Dantas; Sousa Júnior, 2009, p. 14).

A busca de um consenso para o campo das políticas da educação superior foi desenvolvida tanto pelo governo FHC quanto pelo governo Lula, em consonância com parte das diretrizes emanadas pelos organismos multilaterais, procurando-se naturalizar a inexistência da contraposição entre os planos públicos e privados; a defesa do papel do Estado como regulador e controlador da prestação de contas das IES; a ciência e o conhecimento a serviço da economia, dentre outros ${ }^{4}$. Portanto, a reforma da educação superior efetivada no governo Lula optou pela continuidade de várias diretrizes adotadas pelo governo FHC, ao priorizar como papel fundamental das universidades a perspectiva do seu retorno econômico para a sociedade brasileira; ao incentivar a diferenciação e a competição das universidades federais por recursos e na gestão estratégica; ao apoiar parcerias público-privadas, inovação tecnológica e venda de serviços; ao conferir centralidade aos sistemas de avaliação e regulação. Vale dizer que as proposições do Reuni em relação ao aumento de vagas no noturno, à redução da evasão, à ocupação de vagas ociosas, à reestruturação acadêmica foram medidas já preconizadas no governo de FHC (1995-2002) e recomendadas pelo Banco Mundial (1995) que passam pela ótica da racionalização da gestão e da otimização dos custos, que continuaram a ser mantidas no governo Lula. A perspectiva do enfoque na racionalização e na eficiência embasaram os indicadores de desempenho e de performance exigidos pelo Reuni para serem atingidos pelas universidades federais, apesar do significativo financiamento para a expansão da rede de educação superior federal do governo Lula em relação ao governo FHC.

\section{Reforma da educação superior no governo Dilma Rousseff (2011)5: universidade para o desenvolvimento nacional?}

A presidenta Dilma6 iniciou seu governo reafirmando a continuidade do programa de expansão da educação superior do governo Lula mediante o anúncio da construção

\footnotetext{
4. Para maiores detalhes sobre as políticas para a educação superior implementadas pelos governos FHC e Lula que sofreram influência das diretrizes do Banco Mundial, conferir Ferreira e Oliveira (2011).

5. O mandato de Dilma Rousseff encerra-se em 2014.

6. Dilma Rousseff foi Ministra-Chefe da Casa Civil do governo Lula da Silva no período 2005-2010.
} 
de 4 novas universidades federais ${ }^{7}$, da criação de 47 novos campi universitários e de 208 novos IFs. A expansão da educação superior na ótica desse governo tem por objetivo: expandir e interiorizar os institutos e universidades federais, principalmente nos municípios populosos com baixa receita per capita; promover a formação de profissionais para o desenvolvimento regional, bem como estimular a permanência desses profissionais no interior do país; potencializar a função e o engajamento dos institutos e universidades como expressão das políticas do governo na superação da miséria e na redução das iniquidades sociais (BRASIL, 2011a).

Outro programa implantado em 2011 foi o "Ciência Sem Fronteiras", que visa estimular a mobilidade de estudantes, professores e pesquisadores mediante a concessão de bolsas para as áreas consideradas prioritárias/estratégicas em universidades estrangeiras ${ }^{8}$. De acordo com o governo, essa política permitirá

Avançar ciência, tecnologia, inovação e competitividade industrial através da expansão da mobilidade internacional; Aumentar a presença de estudantes e pesquisadores brasileiros em instituições de excelência no exterior; Promover maior internacionalização das universidades brasileiras; Aumentar o conhecimento inovador do pessoal das indústrias brasileiras; Atrair jovens talentos e pesquisadores altamente qualificados para trabalhar no Brasil. (BRASIL, 2011b).

Verificou-se, após o ano de 2005 (final do primeiro mandato do governo Lula), uma significativa expansão da educação superior como política pública e, no caso das universidades federais, uma expansão inicial com a interiorização dos campi. Em seguida, houve a transformação e/ou criação de novas universidades e campi, que também foram instalados na sua maioria no interior do país, tendo como um dos objetivos o impacto na economia local e regional. Essas novas instituições assumem uma configuração na sua quase totalidade de instituições multicâmpus e multirregionais. No governo Dilma, verifica-se o anúncio de um novo ciclo de expansão de universidades mediante a formatação de câmpus temáticos e multicâmpus, da defesa de parâmetros internacionais de comparação de qualidade, do financiamento baseado na eficiência e da presença das grandes universidades. Tais fatores implicam nova configuração, organização e gestão dessas instituições.

7. São elas: Universidade Federal do Sul e Sudeste do Pará, Universidade Federal da Região do Cariri - Ceará; Universidade Federal do Oeste da Bahia e Universidade Federal do Sul da Bahia.

8. São consideradas áreas prioritárias: Engenharias e demais áreas tecnológicas; Ciências Exatas e da Terra: Física, Química, Geociências; Biologia, Ciências Biomédicas e da Saúde; Computação e tecnologias da informação; Tecnologia Aeroespacial; Fármacos; Produção Agrícola Sustentável; Petróleo, Gás e Carvão Mineral; Energias Renováveis; Tecnologia Mineral; Tecnologia Nuclear; Biotecnologia; Nanotecnologia e Novos materiais; Tecnologias de Prevenção e Mitigação de Desastres Naturais; Tecnologias de transição para a economia verde; Biodiversidade e Bioprospecção; Ciências do Mar; Indústria criativa; Novas Tecnologias de Engenharia Construtiva; Formação de Tecnólogos. 
Em 2010, iniciou-se a discussão de um novo modelo para as universidades por meio da criação do consórcio das universidades federais do sul-sudeste mineiro por iniciativa do Governo Federal e, em 2011, ampliou-se esse debate na comunidade acadêmica. Esse novo modelo universitário vem sendo chamado de superuniversidade, megauniversidade ou multiuniversidade. 0 projeto defende a criação de um consórcio entre sete Ifes (Universidades Federais de Alfenas (UNIFALMG), Itajubá (UNIFEI), Juiz de Fora (UFJF), Lavras (UFLA), Ouro Preto (UFOP), São João del-Rei (UFSJ) e Viçosa (UFV)) e sustenta que a incorporação dessas instituições propiciará

a integração acadêmica nas áreas de ensino, pesquisa e extensão, maior eficiência na captação e aplicação de recursos, parcerias para atuação nas áreas de inovação, de novas tecnologias e em outras áreas estratégicas, visando ao desenvolvimento institucional e à capacidade de apresentar propostas para a solução de problemas sociais do Estado de Minas Gerais e do País (PDIC, 2011, p. 4).

As justificativas para a criação do consórcio também evidenciam a proximidade geográfica e a qualidade das atividades desenvolvidas por essas instituições, bem como o fortalecimento das universidades para atender as demandas sociais e econômicas da região. Para a efetivação do consórcio, o governo concederá novo financiamento previsto inicialmente em 20 milhões de reais para as instituições participantes. A tese que fundamenta a importância da criação do consórcio afirma que essas instituições integradas poderão "tornar-se referência nacional e internacional na educação superior, na pesquisa, na extensão, na inovação e na transferência de conhecimento e tecnologias" (PDIC, 2011 p. 5). Os argumentos em defesa de um modelo alternativo de universidade e a possibilidade de assegurar novos recursos vêm despertando o interesse de universidades em outras regiões do país (Silva, 2012).

Outra inovação proposta em relação ao consórcio passa pela criação do primeiro campus multiuniversidade em Caxambu (MG), que deverá ser a sede administrativa e abrigará inicialmente um curso de graduação e a construção de um centro de pesquisa de referência. Porém, estranhamente, até o momento a cidade não acolhe qualquer atividade das sete instituições envolvidas.

Em consonância com os parâmetros que vêm sendo propostos para as universidades federais por meio das reformas na educação superior sobre os novos fins e sobre a relevância desejada para essas instituições, o Plano de Desenvolvimento Institucional do Consórcio das Universidades Federais do Sul-Sudeste de Minas Gerais (PDIC) assume finalidades sociais mais pragmáticas e articuladas com as demandas econômicas ao propor exercer 
influência nessas mesorregiões e em todo o país, destacando-se como importante elemento na promoção do desenvolvimento regional, formação de recursos humanos qualificados, transferência de tecnologia, estímulo e apoio à geração de empreendimentos que comercializam produtos e processos inovadores. (PDIC, 2011, p. 14).

Nas políticas apresentadas para as universidades federais no governo Dilma, alguns elementos ganham destaque e outros reafirmam as proposições do governo Lula, como pode ser verificado nos objetivos que deverão ser cumpridos pelo consórcio: implantar programa de 'mobilidade' consorciada de discentes, docentes e técnicos administrativos, com a implementação inclusive de bolsas; criar núcleos de estudos pedagógicos, para implementação de metodologias de ensino, avaliação da aprendizagem, 'desenhos curriculares, retenção e evasão', sistema de 'avaliação' da graduação, normas e controle acadêmico; 'padronizar os processos de seleção' para a graduação nas universidades consorciadas; ofertar cursos consorciados de graduação, de pós-graduação e de formação continuada em 'áreas estratégicas' para o País; estabelecer política de 'inserção internacional'; desenvolver projetos e formação de núcleos de 'estudos prioritariamente' nas áreas de nanotecnologia, bioenergia, biodiversidade, meio ambiente, sustentabilidade, saúde, educação, biotecnologia e fármacos; incentivar a indução de programas de pesquisa, 'inovação tecnológica e empreendedorismo' mediante as demandas das consorciadas; promover programas e ações consorciadas articulando 'universidade e setor empresarial'; criar mecanismos de gestão da 'internacionalização' do consórcio, dentre outros (PDIC, 2011 - apóstrofos da autora).

A política para a educação superior do governo Dilma vem enfatizando os seguintes parâmetros a serem incorporados pelas universidades: inovação, empreendedorismo, competitividade, formação e atração de capital humano, mobilidade internacional, universidade como agente de desenvolvimento econômico e social, foco em áreas estratégicas/prioritárias de estudo e de pesquisa, internacionalização da educação superior. Sobre empreendedorismo e inovação, de acordo com essa política, parece haver a compreensão de que existe uma correlação positiva e linear entre esses dois fatores e o crescimento econômico no nível local e regional, uma vez que poderá propiciar a criação de novas empresas mediante a transferência de conhecimento, de inovação e de novas tecnologias para a comercialização de serviços e produtos. Já em relação à importância crescente em defesa da formação de capital humano, Neves e Balbachevscky explicam que

uma maior qualificação de recursos humanos é, cada vez mais, considerada pelos governos como fator essencial da competitividade econômica entre os países. Dados empíricos demonstram as taxas de retorno de rendimento e empregabilidade. 0 acesso 
à educação superior também é visto como importante mecanismo de redução da desigualdade de oportunidades e como fator de promoção da mobilidade social. $\mathrm{Ou}$ seja, atribui-se crescente relevância econômica à educação. (Neves; Balbachevscky, 2009, p. 106).

As políticas para a educação superior do governo Lula e Dilma assumiram também a perspectiva da equidade social articulada com a concepção de desenvolvimento econômico, da capacitação de mão de obra e da elevação da empregabilidade da população, principalmente quando faz a opção da construção de campi de instituições federais de educação superior no interior do país. As políticas de ações compensatórias também ganharam destaque com os programas do ProUni e da Universidade Aberta do Brasil. Para Riscal,

a formação de profissionais qualificados em áreas de maior pobreza, por meio de uma política de desenvolvimento regional, possibilitaria, segundo este ponto de vista, às regiões não industrializadas, o desenvolvimento de mão de obra qualificada e consequentemente a recepção de investimentos industriais que vinham se concentrando em regiões de maior concentração de riquezas. (Riscal, 2011, p. 255).

Os governos de Lula e Dilma optaram, como referencial para as reformas sociais propostas e em curso, pela política de estabilidade com crescimento da economia do país. Porém, é interessante observar que o discurso da política para equidade iniciouse no governo de FHC e ganhou projeção no governo de Lula, ao ampliar as áreas de atuação das políticas sociais. 0 governo Dilma até o momento segue a mesma direção. Ganha espaço o discurso da sustentabilidade da economia em detrimento da redistribuição de renda.

\section{Considerações Finais}

As reformas na educação superior, desde 1995, vêm exigindo das universidades uma nova capacidade: transformar o conhecimento em valor econômico e social e, logo, demonstrar sua relevância social para o desenvolvimento do país, seja no âmbito local, regional ou nacional, seja no âmbito internacional. Nessa perspectiva, as universidades devem assumir novas finalidades, como a formação de profissionais qualificados para o mercado de trabalho e para o empreendedorismo, e a geração de conhecimento, tecnologias e inovação a serviço do capital produtivo.

Nessa perspectiva, refletir sobre as finalidades das universidades no Brasil para o século XXI constitui-se em grande desafio para os investigadores desse campo, ao se 
considerar que a universidade possui uma natureza institucional própria, com objetivos e finalidades específicas e distintas de outras instituições. Entender as novas finalidades e concepções propostas para as universidades no cenário da sociedade globalizada, marcada pela acirrada competitividade e pela reestruturação produtiva do capital, frente às novas exigências impostas ao seu modus operandi, sobretudo na sua forma de atuar, de produzir e de se organizar, torna-se imprescindível no atual momento histórico, principalmente para os interessados na defesa da universidade como bem público.

\section{Referências}

AMARAL, Nelson Cardoso. Expansão-avaliação-financiamento: tensões e desafios da vinculação na educação superior brasileira. In: MANCEBO, Deise; SILVA JÚNIOR, João dos Reis da; OLIVEIRA, João Ferreira de; CATANI, Afrânio Mendes. (Orgs.). Reformas da educação superior: cenários passados e contradições do presente. São Paulo: Xamã, 2009. p. 113-146.

AMARAL, Nelson Cardoso. Autonomia e financiamento das Ifes: desafios e ações. Avaliação, Campinas; Sorocaba, v. 13, n. 3, p. 647-680, nov. 2008.

BRASIL. Ministério da Educação. Expansão da educação superior e profissional e tecnológica: mais formação e oportunidades para os brasileiros, 2011a. Disponível em: <http://portal. mec.gov.br/expansao/images/APRESENTACAO_EXPANSAO_EDUCACAO_SUPERIOR14. pdf.> Acesso em: 22 jan. 2012.

. Ministério da Ciência e Tecnologia. Ciências sem fronteiras: um programa especial de mobilidade internacional em ciência, tecnologia e inovação, 2011b. Disponível em: <http://www.mct.gov.br/upd_blob/0217/217221.pdf.> Acesso em: 22 jan. 2012.

Ministério da Educação. O Plano de Desenvolvimento da Educação: razões, princípios e programas, 2007. Disponível em: <http:// portal.mec.gov.br/arquivos/pdf/ livromiolov4.pdf.> Acesso em: $1^{\circ}$ jan. 2012.

. Presidência da República. Lei no 11.096/2005. Institui o Programa Universidade para Todos - PROUNI, regula a atuação de entidades beneficentes de assistência social no ensino superior; altera a Lei $n^{\circ} 10.891$, de 9 de julho de 2004, e dá outras providências. Disponível em: <http://www.planalto.gov.br/ccivil_03/_Ato2004-2006/2005/Lei/L11096. htm. > Acesso em: $1^{\circ}$ jan. 2011.

Presidência da República. Lei no 11.079/2004. Institui normas gerais para licitação e contratação de parceria público-privada no âmbito da administração pública. Disponível em: <http://www.planalto.gov.br/ccivil/_Ato2004-2006/2004/Lei/L11079. htm.> Acesso em: $1^{\circ}$ jan. 2011.

Presidência da República. Lei no 10.861/2004. Institui o Sistema Nacional de Avaliação da Educação Superior - SINAES e dá outras providências. Disponível em: $<$ http://www.planalto. gov.br/ccivil_03/_ato2004-2006/2004/lei//10.861.htm.> Acesso em: 10 jan. 2012. 
. Presidência da República. Lei no 10.973/2004. Dispõe sobre incentivos à inovação e à pesquisa científica e tecnológica no ambiente produtivo e dá outras providências. Disponível em: <http://www.planalto.gov.br/ccivil_03/_ato2004-2006/2004/lei/l10.973.htm.> Acesso em: $1^{\circ}$ fev. 2012.

Presidência da República. Lei n0 9.394/96. Estabelece as Diretrizes e Bases da Educação Nacional. Disponível em: <http://www.planalto.gov.br/ccivil_03/leis/l9394. htm.> Acesso: $1^{\circ}$ jan. 2012.

Ministério da Educação. Decreto n 6.096, de 24 de abril de 2007. Institui o Programa de Apoio a Planos de Reestruturação e Expansão das Universidades Federais - REUNI. Disponível em: <http://portal.mec.gov.br/sesu/arquivos/pdf/diretrizesreuni. pdf.> Acesso em: 2 mar. 2009.

CARVALHO, Cristina Helena Almeida de. Política para o ensino superior no Brasil (1995 2006): ruptura e continuidade nas relações entre público e privado. Anped, $29^{\circ}$ reunião, 2006. Disponível em: <http://www.anped.org.br/reunioes/29ra/trabalhos/trabalho/GT11-2337-In,pdf.> Acesso em: 5 ago. 2009.

CATANI, Afrânio Mendes; HEY, Ana Paula. A educação superior no Brasil e as tendências das políticas de ampliação do acesso. Atos de pesquisa em educação - PPGE/ME FURB, v. 2, n. 3, p. 414-429, set./dez. 2007.

CHAUÍ, Marilena. Escritos sobre a universidade. São Paulo: Unesp, 2001.

CORBUCCI, Paulo Roberto. Financiamento e democratização do acesso à educação superior no Brasil: da deserção do estado ao projeto de reforma. Educação e Sociedade, Campinas, vol. 25, n. 88, Especial, p. 677-701, out. 2004.

CUNHA, Luís Antônio. 0 ensino superior no octênio FHC. Educação e Sociedade, Campinas, vol. 24, n. 82, p. 37-61, abr. 2003.

DANTAS, Éder; SOUSA JÚNIOR, Luiz de. Na contracorrente: a política do governo Lula para a educação superior. Anped, $32^{\circ}$ reunião, 2009. Disponível em: $<\mathrm{http}: / /$ www.anped11. uerj.br/32/gt11-5581--int.pdf.> Acesso em: 6 jan. 2010.

DOURADO, Luiz Fernandes. Políticas e gestão da educação superior: múltiplas regulações e reforma universitária no Brasil. VII Seminário Redestrado - nuevas regulaciones em América Latina, Buenos Aires, 2008. Disponível em: <http://www.fae.ufmg.br/estrado/ cdrom_seminario_2008/textos/ponencias/Ponencia\%20Luiz\%20Fernandes $\% 20$ Dourado.pdf.> Acesso em: 20 ago. 2010.

GOMES, Alfredo Macedo. As reformas e políticas da educação superior no Brasil: avanços e recuos. In: MANCEBO, Deise; SILVA JR., João dos Reis; OLIVEIRA, João Ferreira (Orgs.). Reformas e políticas: educação superior e pós-graduação no Brasil. Campinas: Alínea, 2008. p. 23-51.

FERREIRA, Suely; OLIVEIRA, João Ferreira de. As influências da reforma da educação superior no Brasil e na União Europeia nos papéis sociais das universidades. In: OLIVEIRA, João Ferreira de (Org.). 0 campo universitário no Brasil: políticas, ações e processos de reconfiguração. Campinas, SP: Alínea, 2011, p. 39-62. 
LIMA, Katia. Contra-reforma na educação superior: de FHC a Lula. São Paulo: Editora Xamã, 2007. MAUÉS, Olgaíses. A política de educação superior para a formação e o trabalho docente: a nova regulação educacional. Anped, $31^{\circ}$ Reunião, GT 11, 2008. Disponível em: <http:// anped11.uerj.br.> Acesso em: 5 jan. 2010.

NEVES, Clarissa Baeta; BALBACHEVSKY, Elisabeth. Financiamento da educação superior: lições da experiência internacional. $2^{\circ}$ Ciclo de seminários internacionais. Educação no século XXI: modelos de sucesso. Rio de Janeiro: SENAC, 2009.

OLIVEIRA, João Ferreira de. A reestruturação da educação superior no Brasil e o processo de metamorfose das universidades federais: o caso da Universidade Federal de Goiás. 2000. 210f. Tese (Doutorado em Educação). Faculdade de Educação, Universidade de São Paulo, São Paulo, 2000.

PLANO DE DESENVOLVIMENTO INSTITUCIONAL (PDIC 2011-2015). Consórcio das universidades federais do sul-sudeste de Minas Gerais, versão final, 2011. Disponível em: $\quad<$ http://www.ufsj.edu.br/portal2-repositorio/File/gabin/consorcio/PDIC_versao_ final_23-5-2011.pdf.> Acesso em: 10 fev. 2012.

RISCAL, Sandra A. Política educacional, justiça distributiva e equidade: considerações sobre as políticas compensatórias para a educação. Revista HISTEDBR On-line, n. 44, p. 248-261, dez. 2011.

SILVA JÚNIOR, João dos Reis. Reforma universitária - a nova forma histórica das esferas pública e privada no início do século XXI. In: ORSO, Paulino José (Org.). Educação, sociedade de classes e reformas universitárias. Campinas: Autores Associados, 2007, p. 87-120.

SGUISSARDI, Valdemar. Reforma universitária no Brasil - 1995-2006: precária trajetória e incerto futuro. Educação \& Sociedade, Campinas, vol.27, n. 96, Especial, p.102-156, 2006.

SILVA, Walmir. Cenoura e chicote: o consócio das universidades federais do sul-sudeste mineiro como modelo heteronômico. Universidade e Sociedade, n. 49, jan. 2012.

TEIXEIRA, Pedro Nunes. Financiamento do ensino superior: desafios e escolhas. $2^{\circ}$ Ciclo de seminários internacionais. Educação no século XXI: modelos de sucesso. Rio de Janeiro: SENAC, 2009.

Recebido em abril de 2012

Aprovado em junho de 2012

Suely Ferreira, doutora em Educação pela Universidade Federal de Goiás. Atualmente é professora-adjunta da Faculdade de Educação da Universidade Federal de Goiás. Desenvolve pesquisas na área de educação superior, política educacional e expansão. Participa do Núcleo de Estudo e Documentação Educação, Sociedade e Cultura da UFG. Publicação recente: Universidade: História, metamorfoses e papéis sociais (Cadernos de Pesquisa em Educação PPGE-UFES, v. 17, p. 125-153, 2011). E-mail: suelyferreira13digmail.com. 